Контроллер нагревателя представляет собой конечный автомат (рис. 8).

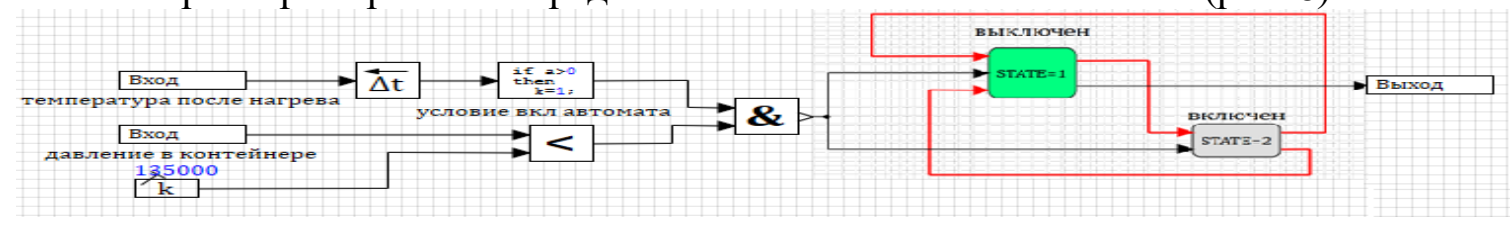

Рис. 8 Конечный автомат

Из рисунка 8 видно, что состояние «Включено» будет активировано при условии, что текущее давление меньше 135000 Па и с выхода блока «Условие вкл. автомата» поступил сигнал, равный 1.

Подсистема «Модель нагревателя» (рисунок 9) реализует процесс нагрева воздуха в контейнере согласно формуле записанной в «Блок программирования».

где - давление, Па; - масса, кг; - температура в контейнере, К. - температура газа из балонов, К. С - удельная теплоемкость воздуха 1000 []; t - время, с.

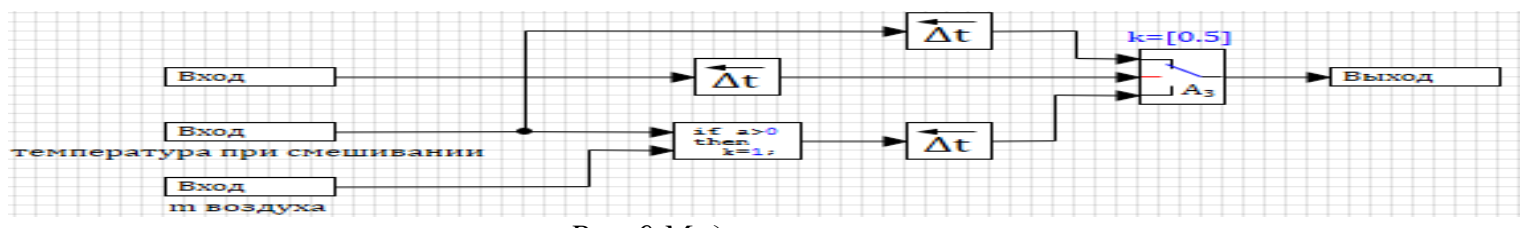

Рис. 9 Модель нагревателя

В подсистеме «Охлаждение» «Модель охладителя» идентична «Модели нагревателя», а так же состав «Контроллера охладителя» идентичен «Контроллеру нагревателя». Отличие представлено только блоком «Условие вкл. автомата».

Таким образом, реализованная в ПК SimInTech модель системы управления транспортным контейнером позволяет прогнозировать поведение объекта в различных ситуациях с целью отработки законов управления.

$$
* * *
$$

1. Пилиневич Л. П., Яшин К. Д. Общая теория систем: методические указания для студ. заоч. формы обуч. по спец. 1-58 0101 - «Инженерно-психологическое обеспечение информационных технологий»/ Л. П. Пилиневич, К. Д. Яшин - Минск.: БГУИР, 2012. - 31с.

2. Конечные автоматы в SimInTech [Электронный ресурс]. - Справочная система SimInTech. - Режим доступа:

http://simintech.ru/webhelp/index.html?q=/webhelp/nachalo_raboti/konechnye_avtomaty_v_simintech.html

\title{
Володько С.C. \\ Определение температур плавления гидридно-кальциевых порошков сплавов Ti50Ni50, Ti28Ni50Hf22 и Ti28Ni50Hf12Zr10 с эффектом памяти формы
}

Тульский государственный университет

doi: $10.18411 /$ sr-10-12-2017-08

(Россия, Тула)

idsp: 000001:sr-10-12-2017-08

\section{Аннотация}

С использованием дифференциальной сканирующей калориметрии определены температуры плавления порошков сплавов Ti50Ni50, Ti28Ni50Hf22 и Ti28Ni50Hf12Zr10. Показано, что легирование бинарного $\mathrm{TiNi}$ более тугоплавкими элементами неоднозначно влияет на его температуру плавления.

Ключевые слова: никелид титана, гидридно-кальциевый метод, эффект памяти формы, температура плавления 
Сплавы с эффектом памяти формы на основе TiNi показывают высокий комплекс физико-механических свойств [1-3], благодаря чему нашли широкое применение в различных отраслях промышленности и техники, где рабочие температуры не превышают $100{ }^{\circ} \mathrm{C}$ [4]. На данный момент особое внимание уделено сплавам с высокотемпературным эффектом памяти формы, среди которых наиболее популярны системы Ti-Ni-Hf, Ti-Ni-Zr и Ti-Ni-Hf-Zr, в первую очередь, из-за их относительно невысокой стоимости по сравнению со сплавами-аналогами систем Ti-Ni-Pd и Ti-Ni-Pt.

В виду несовершенств технологии литья, которая активно применяется для получения сплавов с памятью формы, не удается получать гомогенные по фазовому и химическому составам заготовки массой более чем 1000 грамм [8-11].

В качестве альтернативного метода получения сплавов высокой гомогенности, в том числе сплавов с эффектом памяти формы, выступает гидридно-кальциевый синтез [12]. Предыдущие исследования показали, что технология гидридно-кальциевого синтеза позволяет получать компактные материалы массой до 5 и более килограмм из бинарного TiNi с высокой степенью гомогенности и высоким комплексом физико-механических свойств [15]. Получение компактной заготовки из металлического порошка происходит по средствам процессов консолидации порошка, а именно прессования и его дальнейшего спекания. Твердофазное спекание металлических порошков наиболее активно идет при температурах близких к температурам плавления (0,9 - 0,95·Тпл.) этих сплавов [16], поэтому определение температур плавления порошковых сплавов является важной задачей для разработки оптимального режима спекания.

Гидридно-кальциевый синтез порошков сплавов в общем виде можно представить в виде следующей реакции восстановления:

$$
\mathrm{Me} \text { ' } \mathrm{Me} \text { 'O }+\mathrm{CaH}_{2} \rightarrow \mathrm{Me}^{\prime} \mathrm{Me} "+\mathrm{CaO}+\mathrm{H}_{2} \uparrow
$$

Синтез сплавов проводили в интервале температур $1200{ }^{\circ} \mathrm{C}$. Фазовый состав определяли с использованием автоматизированного дифрактометра ДРОН 3 с использованием монохроматического СuKa излучения с длиной волны $\lambda=1,54178 \AA$. Температуры плавления определяли при помощи сканирующей дифференциальной калориметрии на калориметре NETZSCH STA 449 F3 Jupiter в токе аргона 60 мл/мин со скоростью нагрева $10{ }^{\circ} \mathrm{C} /$ мин. Образцами для исследования послужили порошки сплавов Ti50Ni50, Ti28Ni50Hf22 и Ti28Ni50Hf12Zr10 фракции 150 - 200 мкм

Таблиияа

Фазовый состав порошков сплавов Ti50Ni50, Ti28Ni50Hf22 и Ti28Ni50Hf12Zr10

\begin{tabular}{|c|c|c|c|c|}
\hline Сплав & Фаза & Стр. тип & $\%$ об. & Периоды, нм \\
\hline \multirow{3}{*}{$\mathrm{Ti}_{50} \mathrm{Ni}_{50}$} & В2 - фаза & $\mathrm{cP} 2 / 1$ & 79,5 & $a=0,3009$ \\
\hline & В19' - фаза & $\mathrm{mP} 4 / 2$ & 7,5 & - \\
\hline & R - фаза & $\mathrm{hP} 18 / 61$ & 13 & - \\
\hline \multirow[b]{2}{*}{ Ti28Ni50Hf22 } & В2 - фаза & $\mathrm{cP} 2 / 1$ & 2 & $a=0,3070$ \\
\hline & В19’ - фаза & $\mathrm{mP} 4 / 2$ & 98 & $\begin{array}{l}a=0,3084 \\
b=0,4068 \\
c=0,4921 \\
\beta=103,792\end{array}$ \\
\hline \multirow[b]{2}{*}{ Ti28Ni50Hf12Zr10 } & В2 - фаза & $\mathrm{cP} 2 / 1$ & 3 & $\mathrm{a}=0,3051$ \\
\hline & В19’ - фаза & $\mathrm{mP} 4 / 2$ & 97 & $\begin{array}{l}a=0,3061 \\
b=0,4078 \\
c=0,4882 \\
\beta=103,372\end{array}$ \\
\hline
\end{tabular}




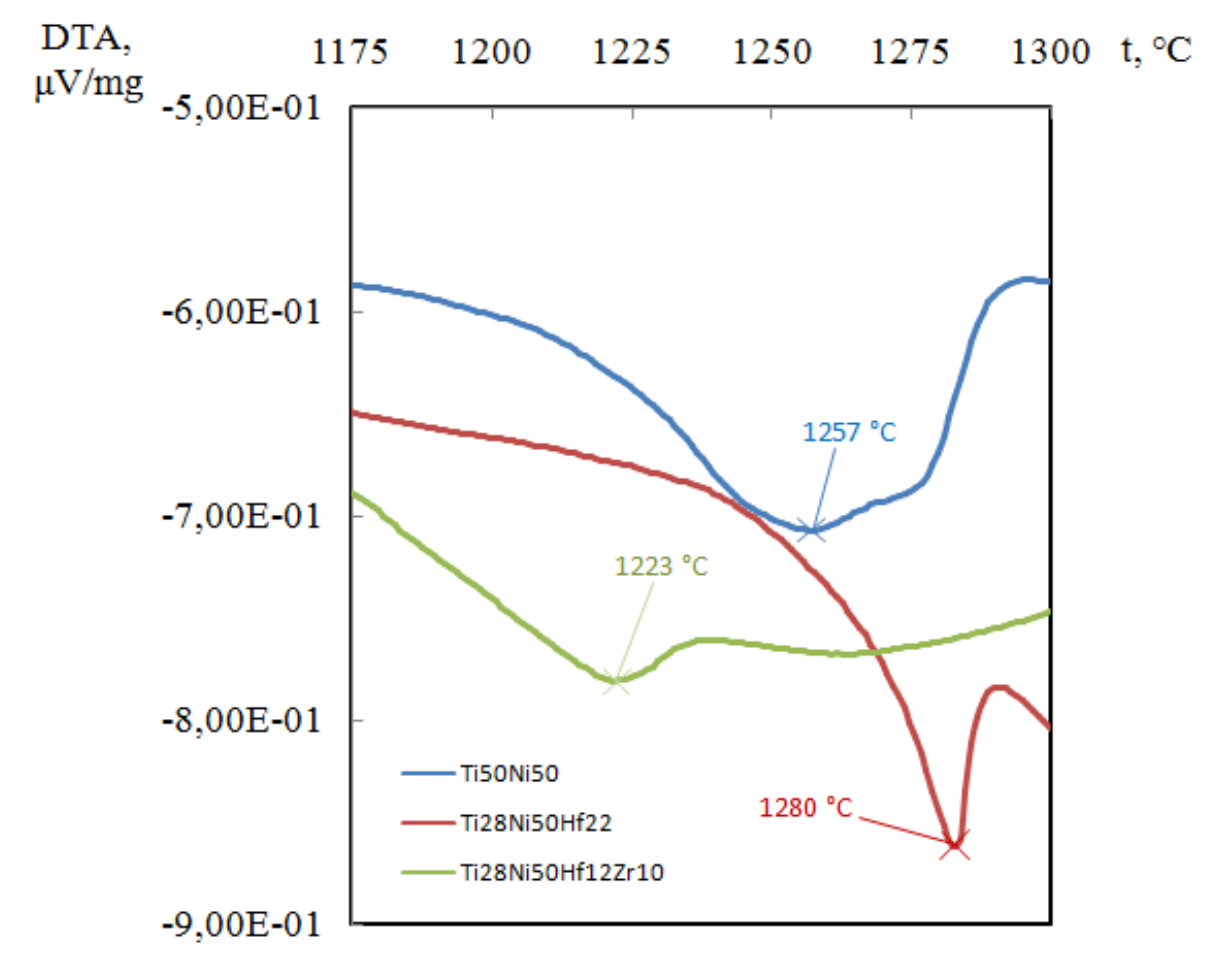

Рисунок - ДСК-кривые порошков сплавов Ti50Ni50, Ti28Ni50Hf22 и Ti28Ni50Hf12Zr10

На рисунке представлены ДСК-кривые для порошков сплавов Ti50Ni50, Ti28Ni50Hf22 и Ti28Ni50Hf12Zr10. На всех трех кривых присутствуют эндотермические пики, которые соответствуют температурам плавления данных сплавов.

В ходе работы были определены температуры плавления порошковых сплавов Ti50Ni50, Ti28Ni50Hf22 и Ti28Ni50Hf12Zr10, которые составили 1257, 1280 и $1223{ }^{\circ} \mathrm{C}$ соответственно. Установлено, что для порошкового гидридно-кальциевого сплава TiNi температура плавления составляет $1257{ }^{\circ} \mathrm{C}$, что на $53{ }^{\circ} \mathrm{C}$ меньше температуры плавления литого сплава согласно [3]. Можно предположить, что это связано с рядом факторов, например адсорбированными газами, дисперсностью порошка, а также отклонением от стехиометрии сплава в порошковом состоянии. Легирование бинарного никелида титана гафнием в количестве 22 ат. \% повышает температуру плавления TiNi. Однако комплексное легирование никелида титана цирконием и гафнием, в количестве 10 и 12 ат. \% соответственно, понижает температуру плавления TiNi. Таким образом, установлено неоднозначное влияние тугоплавких элементов $\mathrm{Zr}$ и $\mathrm{Hf}$ на температуру плавления бинарного порошкового сплава TiNi.

$$
* * *
$$

1. Лихачев В.А., Кузьмин С.Л., Каменцева З.П. Эффект памяти формы. Л.: ЛГУ, 1987. 218 с.

2. Ооцука К., Симидзу К., Судзуки Ю. и др. Сплавы с эффектом памяти формы.М.: Металлургия, 1990. $224 \mathrm{c}$.

3. Хачин В.Н., Пушин В.Г., Кондратьев В.В. Никелид титана: Структура и свойства. М.: Наука, 1992. 160 c.

4. G.S. Firstov, J. van Humbeeck and Y. Koval. High temperature shape memory alloys problems and prospects // Intell. Mater. Syst. Struct. - 2006. Vol. 17. PP $1041-1047$.

5. J. Ma, I. Karaman and R. D. Noebe. High temperature shape memory alloys // Int. Mater. Rev. - 2010. - PP. $257-315$.

6. H.E. Karaca, E. Acar, H. Tobe, S.M. Saghaian. NiTiHf-based shape memory alloys // Materials Science and Technology. - 2014. - PP 1530 - 1544. 
7. R. Noebe, T. Biles, and S.A. Padula. NiTi-based high-temperature shape-memory alloys: properties, prospects and potential applications, in Advanced structural materials: properties, design optimization and applications, (ed. W.O. Soboyejo and T.S. Srivatsan); 2007, New York, Taylor \& Francis Group.

8. Z. Zhang, J. Frenzel, K. Neuking and G. Eggeler. Vacuum Induction of Ternary NiTiX (X = Cu, Fe, Hf, Zr) Shape Memory Alloys Using Graphite Crucibles // Materials Transaction. - 2006. - PP. 661 - 669.

9. М.Ю. Коллеров, А.А. Ильин, И.С. Полькин, А.С. Файнброн, Д.Е. Гусев, С.В. Хачин. Структурные аспекты технологии производства полуфабрикатов из сплавов на основе никелида титана // Металлы. 2007. № 5. c. $77-85$.

10. М.Ю. Коллеров, А.В. Александров, Д.Е. Гусев. Влияние шихтового материала и метода выплавки на структуру и эффект запоминания формы слитков сплавов на основе никелида титана // Технология легких сплавов. 2012. № 2. с. 87 - 93.

11. Y. Tong, F. Chen, B. Tian, L. Li, Y. Zheng. Microstructure and martensitic transformation of Ti49Ni51-xHfx high temperature shape memory alloys // Materials Letters. - 2009. PP. $1869-1871$.

12. Касимцев А.В. Физико-химия и технология получения порошков интерметаллидов, тугоплавких соединений и композиционных материалов гидридно-кальциевым методом: автореф. дис. докт. техн. наук: 05.16.06. - М: Национальный исследовательский технологический университет «МИСиС», 2010. $-44 \mathrm{c}$.

13. А.В. Касимцев, Г.В. Маркова, А.В. Шуйцев, Ю.В. Левинский, Т.А. Свиридова, А.В. Алпатов, Изменение структуры при консолидации гид-ридно-кальциевых порошков интерметаллида TiNi // Металлург 2014. № 11. С. 108-114.

14. А.В. Касимцев, Г.В. Маркова, А.В. Шуйцев, Ю.В. Левинский, Т.А. Свиридова, А.В. Алпатов, Порошковый гидридно-кальциевый интерме-таллид TiNi // Известия ВУЗов. Порошковая металлургия и функциональные покрытия. 2014. № 3. С. 31-37.

15. А.В. Касимцев, Г.В. Маркова, А.В. Шуйцев, Т.А. Свиридова, С.С.Володько. Изменение структуры и свойств порошкового гидридно-кальциевого никелида титана при ротационной ковке // Технология легких сплавов. 2016. № 3. С. 44 - 52.

16. Процессы порошковой металлургии. В 2-х т. Т. 2. Формование и спекание: Учебник для вузов / Либенсон Г.А., Лопатин В.Ю., Комарницкий Г.В. - М.: МИСИС, 2002. - 320 с.

\section{Грачев С.П. \\ Моделирование и анализ точности механической обработки методом конечных элементов \\ ФГБОУ ВО Вятский государственный университет (Россия, Киров)}

doi: $10.18411 / \mathrm{sr}-10-12-2017-09$

idsp: 000001:sr-10-12-2017-09

Аннотация

В статье рассмотрен пример анализа точности обработки детали малой жесткости путем моделирования напряженно-деформированного состояния процесса механической обработки методом конечных элементов.

Ключевые слова: технологическая подготовка производства, точность обработки, метод конечных элементов.

Наиболее трудоемкий и ответственный этап подготовки производства нового изделия - этап технологической подготовки производства. Ошибки при выборе стратегических решений, определяющих операции технологических процессов, варианты конструкций оснастки, специального инструмента, в дальнейшем оборачиваются значительными экономическими потерями.

Использование методов математического моделирования, особенно на первых этапах технологической подготовки, уменьшает вероятность возможных ошибок, повышает качество работ, снижает затраты и сроки технологической подготовки.

Данная статья посвящена исследованию напряженно-деформированного состояния процесса механической обработки детали малой жесткости, с целью оценки точности, получаемых после обработки размеров.

Деталь, в виде тонкого кольца, изготавливается из титанового сплава. 